\title{
Bone turnover during high dose inhaled corticosteroid treatment
}

\author{
N J Ali, S Capewell, $M$ J Ward
}

\begin{abstract}
This study was performed to determine the effects of high doses of two inhaled corticosteroids, beclomethasone dipropionate and budesonide, on biochemical indices of bone turnover (urinary hydroxyproline:creatinine and calcium: creatinine ratios, plasma alkaline phosphatase, and parathyroid hormone). Twelve healthy male doctors, aged 25-36 (mean 30) years, were studied. After a week's run in period eight subjects inhaled beclomethasone dipropionate 2000 $\mu \mathrm{g} / \mathrm{day}$ and eight inhaled budesonide $1800 \mu \mathrm{g} /$ day for 28 days; this was followed by a week without any treatment. During treatment with beclomethasone dipropionate there was a significant increase in the hydroxyproline:creatinine ratio (a $46 \%$ increase at 28 days), and a fall in serum alkaline phosphatase activity (a $7 \cdot 4 \%$ fall at 28 days). There were no significant changes during budesonide treatment. Thus high dose inhaled beclomethasone dipropionate increased biochemical markers of bone resorption and reduced serum alkaline phosphatase, a marker of bone mineralisation. A prospective study in asthmatic patients is indicated to assess the long term effects of high dose inhaled corticosteroids on bone mass.
\end{abstract}

Since their introduction two decades ago inhaled corticosteroids have become the cornerstone of the treatment of chronic asthma. Initially beclomethasone dipropionate and later budesonide were used in doses of up to $800 \mu \mathrm{g} /$ day but higher doses, up to $2000 \mu \mathrm{g} /$ day, have become commonplace, to improve control in patients with unstable asthma and to allow the dose of oral corticosteroids to be reduced..$^{1-3}$ This trend has been encouraged by the undoubted efficacy and safety of inhaled corticosteroids by comparison with oral corticosteroids. ${ }^{1}$ Unwanted local effects of inhaled corticosteroids such as dysphonia and oral candidiasis are relatively common but usually mild and reversible. ${ }^{4}$ Of more concern are the systemic effects that may occur with higher doses $(1500 \mu \mathrm{g} /$ day or more), which include adrenal suppression ${ }^{5}$ and impaired metabolism of glucose and lipids. ${ }^{6}$ Evidence of other systemic effects, such as cutaneous atrophy ${ }^{7}$ and cataract formation, ${ }^{8}$ is emerging and raises the possibility of more serious unwanted complications of long term corticosteroid treatment, such as osteoporosis.

Reid et al reported that total body calcium (and by inference bone mass) was $8.8 \%$ less in asthmatic patients taking inhaled corticosteroids than in asthmatic control subjects. Although their conclusions have been questioned because information about the use of systemic corticosteroids was obtained retrospectively, ${ }^{10}$ the implications are serious enough to require further study.

We therefore studied the effects of four week's treatment with inhaled corticosteroids on biochemical indices of bone turnover, comparing beclomethasone dipropionate $2000 \mu \mathrm{g}$ with budesonide $1800 \mu$ g daily. The study was conducted in normal men to avoid the confounding effects on bone metabolism of concurrent or previous treatment with corticosteroids, or differences in sex steroids between the sexes.
Department of Chest Diseases

N J Ali

$S$ Capewell

Department of Clinical

Pharmacology

M J Ward

University of Wales

College of Medicine, Llandough Hospital, Penarth CF6 1XX

Address for reprint requests: Dr Ali, Osler Chest Unit, Churchill Hospital, Oxford OX3 7L J

Accepted 3 December 1990
Table 1 Mean (SD) values for the ratios of hydroxyproline to creatinine concentration ( $\mu m o l / m m o l)$ and of calcium to creatinine concentration ( $\mu \mathrm{mol} / \mathrm{mmol}$ ) and for parathyroid hormone concentration (IU/l) and alkaline phosphatase activity (IU/l) before, during, and after treatment with beclomethasone dipropionate (BDP) and budesonide (BUD) in 12 normal subjects ${ }^{\star}$

\begin{tabular}{|c|c|c|c|c|c|}
\hline & & Baseline & Day 14 & Day 28 & Day 35 \\
\hline Hydroxyproline: creatinine & $\begin{array}{l}\text { BDP } \\
\text { BUD }\end{array}$ & $\begin{array}{l}13.7(6.6) \\
13.4(5.6)\end{array}$ & $\begin{array}{l}17 \cdot 1(5 \cdot 7) \\
15 \cdot 1(6 \cdot 8)\end{array}$ & $\begin{array}{l}20 \cdot 1(4 \cdot 9) \\
12 \cdot 4(7 \cdot 4)\end{array}$ & $\begin{array}{l}14.8(6.9) \\
11.5(6.8)\end{array}$ \\
\hline & $\begin{array}{l}\text { BDP } \\
\text { BUD }\end{array}$ & $\begin{array}{l}139(45) \\
155(64)\end{array}$ & $\begin{array}{l}156(59) \\
136(32)\end{array}$ & $\begin{array}{l}181(49) \\
148(49)\end{array}$ & $\begin{array}{l}124(48) \\
133(32)\end{array}$ \\
\hline Alkaline phosphatase & $\begin{array}{l}\text { BDP } \\
\text { BUD }\end{array}$ & $\begin{array}{l}73.6(16.6) \\
78.7(22.7)\end{array}$ & $\begin{array}{l}69.1(16.2) \\
79.7(23.8)\end{array}$ & $\begin{array}{l}68 \cdot 1(12 \cdot 4) \\
77 \cdot 5(20 \cdot 6)\end{array}$ & $\begin{array}{l}66 \cdot 8(14 \cdot 8) \\
76 \cdot 8(18)\end{array}$ \\
\hline Parathyroid hormone & $\begin{array}{l}\text { BDP } \\
\text { BUD }\end{array}$ & $\begin{array}{l}4.0(1.2) \\
3.6(1.1)\end{array}$ & - & $\begin{array}{l}4.2(0.9) \\
3.4(1.2)\end{array}$ & $\begin{array}{l}4.4(0.6) \\
3.9(1.0)\end{array}$ \\
\hline
\end{tabular}

^Eight took part in each limb of the study. 
Table 2 Summary of areas under the curves (AUC) for the individual subjects ${ }^{\star}$

\begin{tabular}{|c|c|c|c|c|c|c|}
\hline \multirow[b]{2}{*}{ Subject No } & \multicolumn{3}{|c|}{ Beclomethasone } & \multicolumn{3}{|c|}{ Budesonide } \\
\hline & $H P: C r$ & Alk Ph & $\mathrm{Ca}: \mathrm{Cr}$ & $H P: C r$ & Alk Ph & $\mathrm{Ca}: \mathrm{Cr}$ \\
\hline $\begin{array}{l}1 \\
2 \\
3 \\
4 \\
5 \\
6 \\
7 \\
8 \\
8\end{array}$ & $\begin{array}{r}29 \\
177 \\
176 \\
131 \\
-10 \\
96 \\
92 \\
197\end{array}$ & $\begin{array}{r}-196 \\
-102 \\
-228 \\
-17 \\
-189 \\
-55 \\
-445 \\
-19\end{array}$ & $\begin{array}{r}-1652 \\
343 \\
490 \\
1711 \\
-875 \\
1148 \\
3283 \\
805\end{array}$ & $\begin{array}{r}33 \\
-18 \\
185 \\
11 \\
-129 \\
95 \\
-103 \\
-123\end{array}$ & $\begin{array}{r}-14 \\
7 \\
-123 \\
7 \\
-130 \\
42 \\
-28 \\
196\end{array}$ & $\begin{array}{r}-890 \\
-455 \\
-315 \\
-1218 \\
350 \\
1213 \\
1197 \\
-5486\end{array}$ \\
\hline Sum of AUC & 886 & -1251 & 5253 & $-49 \dagger$ & $-43 t$ & -5151 \\
\hline
\end{tabular}

*Subjects $1-4$ took part in both limbs of the study.

HP:Cr - hydroxyproline:creatinine ratio; $\mathrm{Ca}: \mathrm{Cr}$-calcium:creatinine ratio; Alk $\mathrm{Ph}$-alkaline phosphatase activity. tp $<0.05$ in the comparison with beclomethasone.

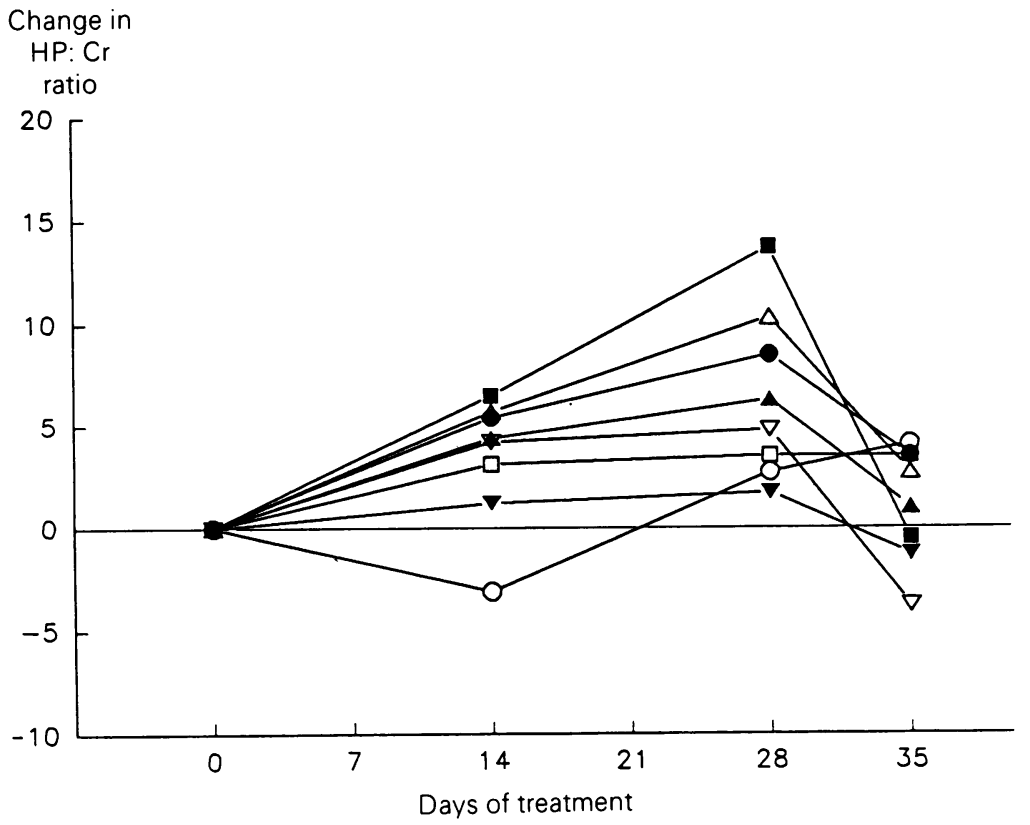

(a)

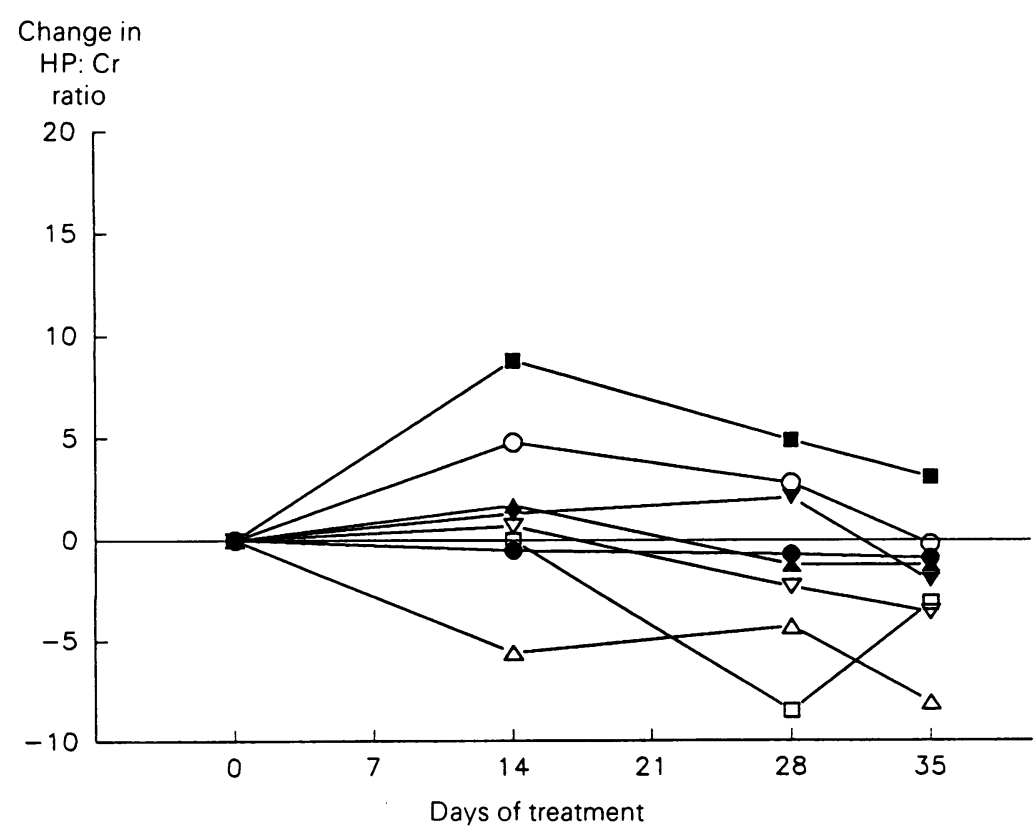

(b)

Figure 1 Change in the ratio of hydroxyproline to creatinine ( $\mathrm{Hp}: \mathrm{Cr}$ ) concentration ( $\mu \mathrm{mol} / \mathrm{mmol}$ ) from baseline during treatment with (a) beclomethasone dipropionate $2000 \mu g / d a y$ and $(b)$ budesonide $1800 \mu g / d a y$ for individual subjects. The four subjects who took part in both limbs of the study are indicated by filled in symbols.
SUBJECTS

Twelve healthy men (mean age 30 , range 2536 years) were recruited from hospital medical staff. Four took part in both limbs of the study.

PROTOCOI

After a seven day run in period without treatment (days -7 to 0 ) subjects inhaled $2000 \mu \mathrm{g}$ beclomethasone dipropionate or $1800 \mu \mathrm{g}$ budesonide daily via the appropriate spacer device (Volumatic or Nebuhaler) for four. weeks (days 0 to 28). This was followed by a week without any treatment (days 29 to 35 ). For the four subjects who took part in both limbs of the study at least three months elapsed between treatments.

\section{SAMPLES}

Samples were collected at the beginning and end of the run in period (days -7 and 0 ), after two and four weeks' treatment (days 14 and 28), and a week after treatment had stopped (day 35). Subjects refrained from heavy exertion and from alcohol for 24 hours before collections were made.

The following samples were collected, after a 12 hour overnight fast: (a) Urine produced in the first two hours after initial voiding, for measurement of hydroxyproline, calcium, and creatinine; (b) uncuffed blood for measurement of urea, electrolytes, calcium, phosphate, creatinine, alkaline phosphatase, and parathyroid hormone.

Total urinary hydroxyproline was measured by a colorimetric method, ${ }^{11}$ parathyroid hormone by immunoassay, ${ }^{12}$ and alkaline phosphatase by standard methods.

\section{ANALYSIS}

The means of the values for the two pretreatment samples were taken as the baselines for each subject. To determine whether the treatments had a significant effect on bone turnover, the area under the curve of the change in each variable plotted against time was calculated for each subject. The significance of this change was tested by the paired $t$ test on the assumption that without treatment the baseline would have remained stable-that is, that the area under the baseline would be zero. ${ }^{13}$ To compare the effects of the two treatments on indices of bone turnover the areas under 


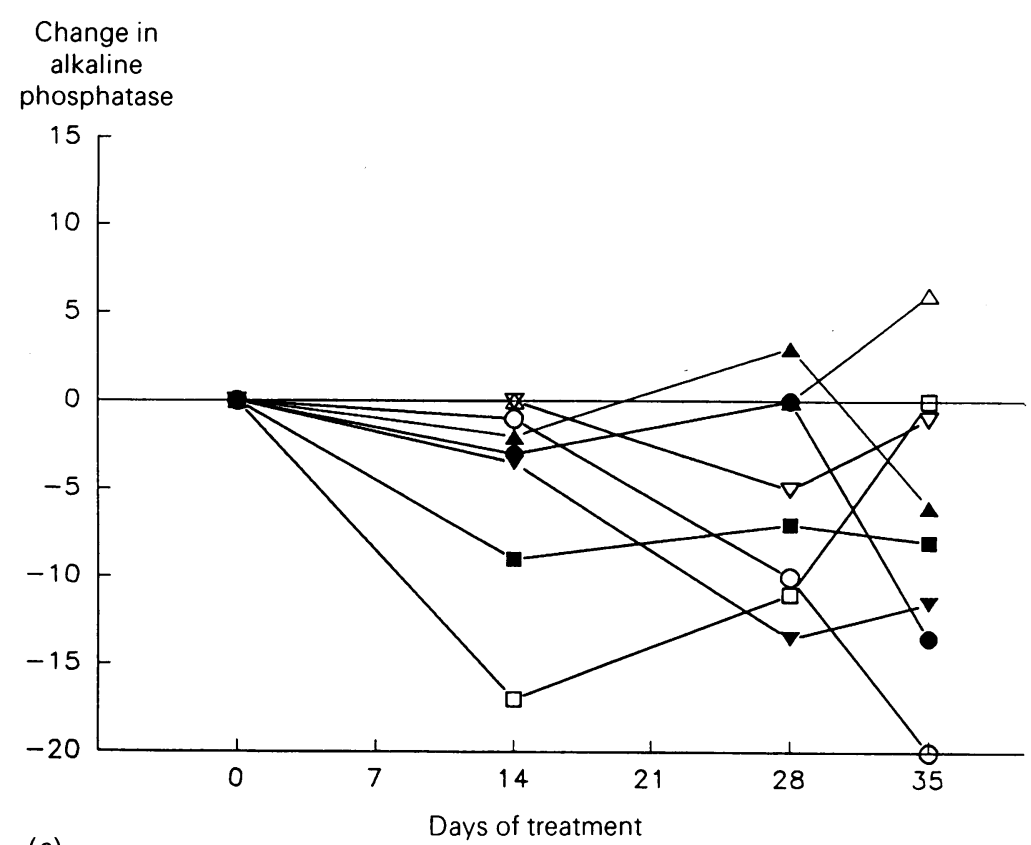

(a)

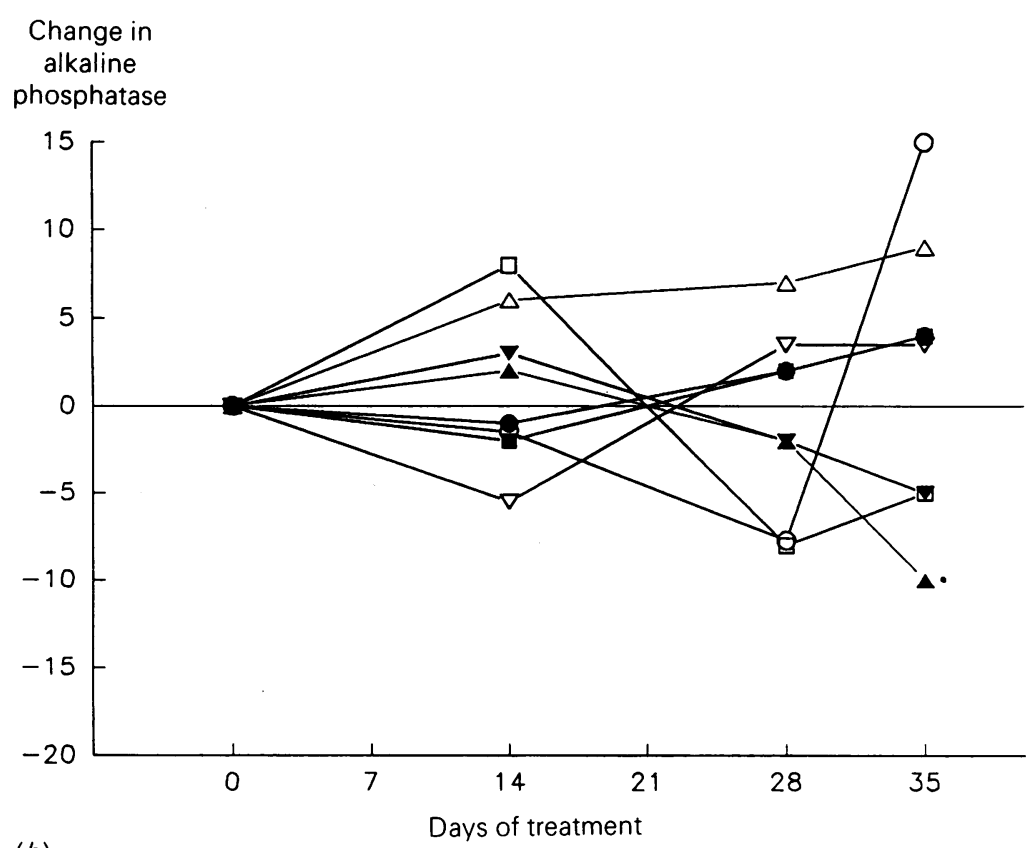

(b)

Figure 2 Change in alkaline phosphatase activity (IU/l) from baseline during treatment with (a) beclomethasone dipropionate $2000 \mu \mathrm{g} /$ day and (b) budesonide $1800 \mu \mathrm{g} /$ day for individual subjects. Symbols as in figure 1.

the curves of each measured variable were compared by means of the unpaired $t$ test.

The study was approved by the local medical ethics committee and all subjects gave informed consent.

\section{Results}

Mean values of the different variables at the different times of measurement and the areas under the time-response curves are given in tables 1 and 2 .

HYDROXYPROLINE: CREATININE RATIO

The changes from baseline in the ratio of hydroxyproline to creatinine concentration for the eight subjects during beclomethasone treatment are shown in figure $1 a$. The area under the curves of change in the hydroxyproline:creatinine ratio differed significantly from zero $(p<0.005)$. The ratio had risen by 14 days in all but one subject and was maximal in all after 28 days (mean increase $6.4 \mu \mathrm{mol} /$ mmol, a $46 \%$ rise at 28 days). After treatment had stopped values had fallen towards baseline in seven of the eight subjects. With budesonide treatment there was no significant change from baseline, and no consistent pattern of change (fig 1b). The areas under the curves for beclomethasone and budesonide were significantly different $(p<0.05)$.

\section{ALKALINE PHOSPHATASE}

The area under the curves of change in alkaline phosphatase activity during beclomethasone treatment was significantly different from zero $(\mathrm{p}<0.02)$-mean fall $5.5 \mathrm{IU} / 1$, a $7.4 \%$ decrease (table 1). There was no significant change during budesonide treatment (fig 2). Comparison of the areas under the curves for the two drugs showed them to be significantly different $(p<0.05)$.

\section{CALCIUM:CREATININE RATIO AND PARATHYROID HORMONE}

There were no significant changes in the ratio of urinary calcium to creatinine concentration or in parathyroid hormone during treatment with either drug, and no significant difference in the areas under the curves for the calcium: creatinine ratio between the two drugs (fig 3 and table 1).

\section{Discussion}

The potential confounding effects of previous corticosteroid treatment in asthmatic subjects led us to study the effect of high dose inhaled corticosteroids in normal subjects. We observed a significant increase in a biochemical marker of bone resorption (hydroxyproline: creatinine ratio) and a fall in a marker of mineralisation (alkaline phosphatase) during treatment with high dose inhaled beclomethasone.

The urinary hydroxyproline:creatinine ratio in fasting subjects is a measure of bone resorption that correlates well with histological and kinetic measures. Raised values are almost always seen in conditions with high bone turnover-for example, Paget's disease of bone, perimenopausal bone loss, and hyperparathyroidism. ${ }^{14} 15$ In our study the hydroxyproline:creatinine ratio rose by $46 \%$ after 28 days' treatment with beclomethasone. The prompt return of the ratio towards baseline one week after the end of treatment suggests that this increase was a direct effect of the inhaled drug. No such trend was apparent in the group taking budesonide. Budesonide treatment in a dose that has been shown to be clinically equivalent $(1800 \mu \mathrm{g} / \text { day })^{16}$ did not cause significant changes in any of the indices of bone 


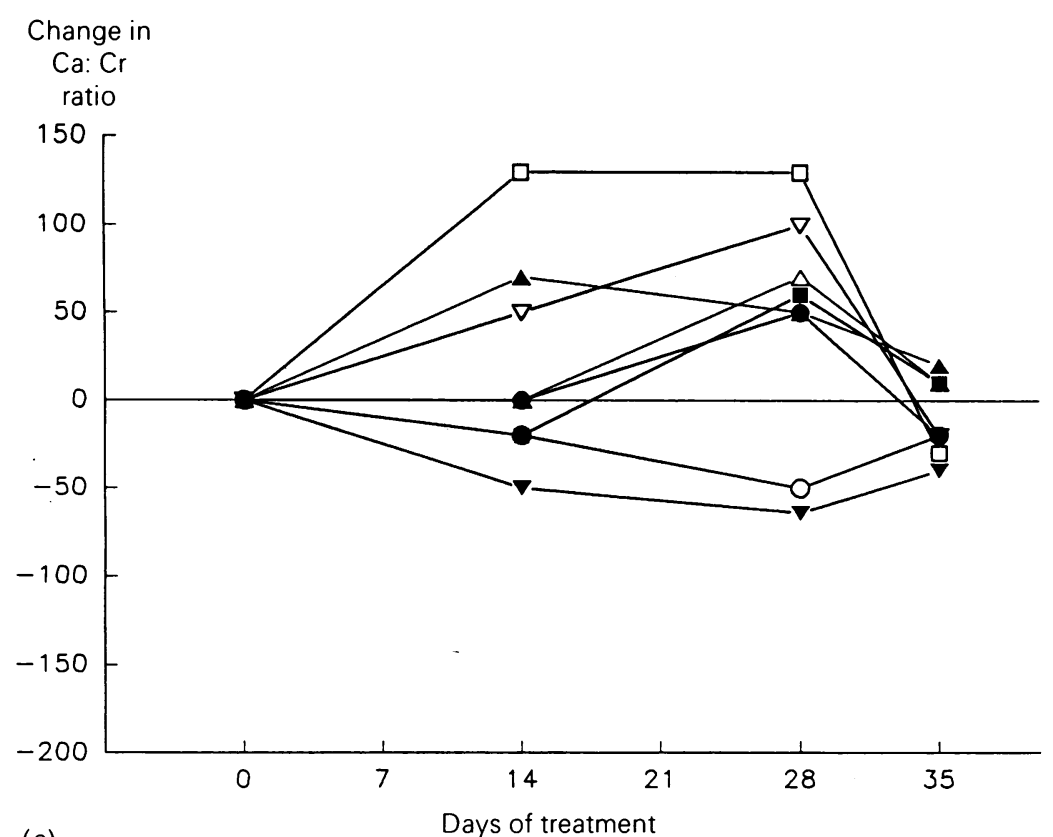

(a)

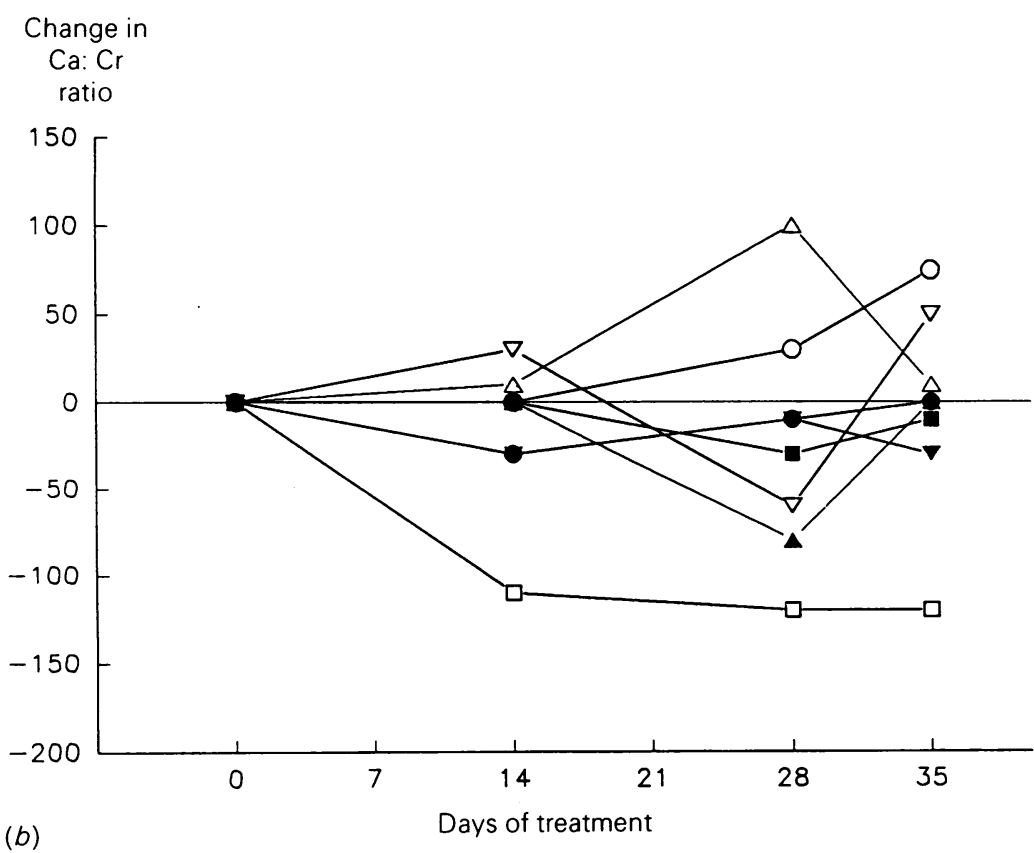

Figure 3 Change in the ratio of calcium to creatinine (Ca:Cr) concentration ( $\mu$ mol) mmol) from baseline during treatment with (a) beclomethasone dipropionate $2000 \mu \mathrm{g}$ day and (b) budesonide $1800 \mu \mathrm{g} /$ day for individual subjects. Symbols as in figure 1.

turnover measured. This is consistent with the results of Toogood et al, who used a higher dose of budesonide for a shorter period. ${ }^{17}$ The apparent differences in effect between beclomethasone and budesonide on bone metabolism may reflect the lower systemic bioavailability of budesonide. Budesonide has a much higher first pass clearance, with a bioavailability of only $11 \%$ after oral administration. It is degraded to its major inactive metabolite four times faster than beclomethasone, and this is the suggested reason for its smaller effect on the hypothalamic-pituitaryadrenal axis. ${ }^{18} 19$

In a study of patients treated with $20 \mathrm{mg}$ prednisone for one month Gennari et al found at $77 \%$ increase in the urinary hydroxyproline: creatinine ratio. ${ }^{20}$ Our results therefore suggest that $2000 \mu \mathrm{g}$ of inhaled beclomethasone a day has at least half the magnitude of effect of $20 \mathrm{mg}$ of prednisone on bone resorption. Beclomethasone is thought to be about five to six times as potent as prednisone in terms of its ability to suppress the hypothalamo-pituitary-adrenal axis when administered systemically. ${ }^{21}$ This implies either that much of the inhaled drug is acting systemically (which is unlikely as an appreciable amount is deposited in the mouth, ${ }^{22}$ absorbed via the gastrointestinal tract, and inactivated by the liver $)^{23}$ or that bone metabolism is more sensitive to beclomethasone than is the hypothalamo-pituitary-adrenal axis, the traditional method for comparing corticosteroid potency.

Although the mean calcium:creatinine ratio rose by $33 \%$ after 28 days of beclomethasone treatment this did not reach statistical significance. Toogood et al ${ }^{17}$ have suggested that high dose inhaled budesonide may alter the diurnal excretion of calcium, less being produced in the early morning. We may therefore have missed a significant effect on 24 hour calcium excretion by collecting morning samples only. Nevertheless, the size of the increase in the calcium:creatinine ratio resembles that of the hydroxyproline:creatinine ratio and again suggests that bone resorption had increased.

Alkaline phosphatase is produced by osteoblasts during bone formation, and in the absence of liver dysfunction the total serum levels reflect mineralisation rates. ${ }^{15} 16$ The significant fall in alkaline phosphatase activity during beclomethasone treatment suggests that in addition to the increase in bone resorption there may be a fall in mineralisation, indicating that bone metabolism had been uncoupled.

Corticosteroids are thought to cause osteoporosis by several mechanisms, which have been reviewed recently. ${ }^{24}$ The mechanisms include a direct effect on bowel mucosa, leading to reduced calcium absorption, and a degree of hyperparathyroidism. In this study beclomethasone did not increase parathyroid hormone significantly. In addition to increasing renal calcium excretion corticosteroids interact with osteoclast receptors to increase bone resorption and suppress adrenal androgen production and osteoblast protein synthesis.

High dose inhaled beclomethasone produced effects on bone turnover even when given for the relatively short period of four weeks. Admittedly, none of the measured variables moved outside their normal ranges, and the effects we have found may not represent the state of affairs during long term treatment. Nevertheless, bone mass is the result of a dynamic balance between formation and resorption and small shifts in the balance, if sustained, may lead to significant loss of bone mass and symptomatic osteoporosis. Inhaled corticosteroids will remain the drugs of choice in chronic asthma for the forseeable future. Prospective studies of bone mass in asthmatic patients taking inhaled corticosteroids are therefore required to determine whether the changes we have found are translated into 
substantial loss of bone mass with prolonged treatment.

We are grateful to Dr K W Davies for the biochemical assays, and above all to the 12 volunteers: AS, JT, ST, DM, NA, MW, $\mathrm{JB}, \mathrm{RW}, \mathrm{PD}, \mathrm{JS}, \mathrm{AP}$, and SC

1 Smith MJ. The place of high dose inhaled corticosteroids in asthma therapy. Drugs 1987;33:423-29.

2 Smith MJ, Hodson ME. High dose beclomethasone inhale in the treatment of asthma. Lancet 1983;i:265-9.

3 Anonymous. High dose corticosteroid inhalers for asthma. [editorial]. Lancet 1984;ii:23.

4 Stead RJ, Cook NJ. Adverse effects of inhaled corticosteroids. BMJ 1989;298:403

5 Smith MJ, Hodson ME. Effects of long term inhaled high dose beclomethasone dipropionate on adrenal function. Thorax 1983;38:676-81.

6 Kruszynska YT, Greenstone M, Home PD, Cooke NJ. Effect of high dose inhaled beclomethasone dipropionate on carbohydrate and lipid metabolism in normal subjects. Thorax 1987;42:881-4.

7 Capewell S, Reynolds S, Shuttleworth D, Edwards C Finlay AY. Purpura and dermal thinning associated with high dose inhaled corticosteroids. BMJ 1990;300: 1548-51.

8 Karim AKA, Thompson GM, Jacob TJC. Steroid aerosols and cataract formation. $B M J 1989 ; 299: 918$.

9 Reid DM, Nicoll JJ, Smith MA, Higgins B, Tothill P, Nuki $G$. Corticosteroids and bone mass in asthma; comparison with rheumatoid arthritis and polymyalgia rheumatica. $B M J$ 1986;293:1463-6.

10 Crompton GK. Corticosteroids and bone mass in asthma. $B M J$ 1987;294:123.

11 Kivirikko KI, Laitinen O, Prokop DJ. Modification of a specific assay for hydroxyproline in urine. Anal Biochem 1967;19:249-55.

12 Brown RC, Aston JP, Weeks I, Woodhead JS. Circulating intact parathyroid hormone measured by immunochemiluminometric assay. J Clin Endocrinol Metab 1987;65: 407-14.

13 Mathews JNS, Altman DG, Campbell MJ, Royston P. Analysis of serial measurements in medical research. BMJ 1990;300:230-5.

14 Nordin BEC. Diagnostic procedures in disorders of calcium metabolism. Clin Endocrinol 1978;8:55-67.

15 Charles P, Pser JW, Mosekilde L, Jensen FT. Estimation of bone turnover by $47 \mathrm{Ca}$ kinetics. J Clin Invest 1985; 76:2254-8.

16 Ebden P, Jenkins A, Houston G, Davies BH. Comparison of two high dose corticosteroid treatments, beclomethasone dipropionate $(1500 \mu \mathrm{g} /$ day $)$ and budesonide $(1600 \mu \mathrm{g}$ day), for chronic asthma. Thorax 1986;41:869-74.

17 Toogood JH, Crilly RG, Jones G, Nadeau J, Wells GA Effect of high inhaled budesonide on calcium and phosphate metabolism and the risk of osteoporosis. Am Rev phate metabolism and the

18 Ryrfeldt A, Andersson P, Edsbacker S, Tonnersson M Davies D, Pauwels R. Pharmokinetics and metabolism of budesonide: a selective glucocorticoid. Eur J Repir Dis 1982;63(suppl 122):86-95.

19 Pedersen S, Fugslang G. Urine cortisol excretion in children treated with high doses of inhaled corticosteroids: a comparison of budesonide and beclomethasone. Eur $J$ Respir Dis 1988;1:433-5.

20 Gennari C, Imbimbo B, Montagnani M, Bernini M, Nardi $P$, Avioli LV. Effects of prednisone and deflazacort on mineral metabolism and parathyroid hormone activity in humans. Calcif Tissue Int 1984;36:245-52.

21 Harris DM. Some properties of beclomethasone dipropionate and related steroids in man. Postgrad Med $J$ 1975; 51(suppl 4):20-5.

22 Newman SP, Miller AB, Lennard-Jones TR, Moren F Clarke SW. Improvement of pressurized aeroso deposition with nebuhaler spacer device. Thorax 1984;39: 935-41.

23 Martin LE, Harrison C, Tanner RJN. Metabolism of beclomethasone dipropionate by animals and man. Postgrad Med J 1975;51(suppl 4):11-20.

24 Reid IR. Pathogenesis and treatment of steroid osteoporosis Clin Endocrinol 1989;30:83-103. 